\title{
Variability of forced vital capacity in progressive interstitial lung disease: a prospective observational study
}

\author{
Tobias Veit ${ }^{1,2}$, Michaela Barnikel ${ }^{1,2}$, Alexander Crispin ${ }^{3}$, Nikolaus Kneidinger ${ }^{1,2}$, Felix Ceelen ${ }^{1,2}$, Paola Arnold ${ }^{1,2}$ \\ Dieter Munker ${ }^{1,2}$, Magdalena Schmitzer ${ }^{1,2}$, Jürgen Barton ${ }^{1,2}$, Sanziana Schiopu ${ }^{1,2}$, Herbert B. Schiller ${ }^{2}$, \\ Marion Frankenberger ${ }^{2}$, Katrin Milger ${ }^{1,2}$, Jürgen Behr ${ }^{1,2,4}$, Claus Neurohr ${ }^{5}$ and Gabriela Leuschner ${ }^{1,2^{*}}$ (D)
}

\begin{abstract}
Background: Fibrotic interstitial lung disease (ILD) is often associated with poor outcomes, but has few predictors of progression. Daily home spirometry has been proposed to provide important information about the clinical course of idiopathic pulmonary disease (IPF). However, experience is limited, and home spirometry is not a routine component of patient care in ILD. Using home spirometry, we aimed to investigate the predictive potential of daily measurements of forced vital capacity (FVC) in fibrotic ILD.
\end{abstract}

Methods: In this prospective observational study, patients with fibrotic ILD and clinical progression were provided with home spirometers for daily measurements over 6 months. Hospital based spirometry was performed after three and 6 months. Disease progression, defined as death, lung transplantation, acute exacerbation or FVC decline $>10 \%$ relative was assessed in the cohort.

Results: From May 2017 until August 2018, we included 47 patients (IPF $n=20$; non-IPF $n=27$ ). Sufficient daily measurements were performed by $85.1 \%$ of the study cohort. Among these 40 patients (IPF $n=17$; non-IPF $n=23$ ), who had a mean \pm SD age of $60.7 \pm 11.3$ years and FVC $64.7 \pm 21.7 \%$ predicted $(2.4 \pm 0.8 \mathrm{~L}), 12$ patients experienced disease progression (death: $n=2$; lung transplantation: $n=3$; acute exacerbation: $n=1$; FVC decline $>10 \%: n=6$ ). Within the first 28 days, a group of patients had high daily variability in FVC, with $60.0 \%$ having a variation $\geq 5 \%$. Patients with disease progression had significantly higher FVC variability than those in the stable group (median variability $8.6 \%$ vs. $4.8 \% ; p=0.002$ ). Cox regression identified FVC variability as independently associated with disease progression when controlling for multiple confounding variables (hazard ratio: 1.203; 95\% Cl:1.050-1.378; $p=$ 0.0076).

Conclusions: Daily home spirometry is feasible in IPF and non-IPF ILD and facilitates the identification of FVC variability, which was associated with disease progression.

Keywords: Interstitial lung disease, Idiopathic pulmonary fibrosis, Home spirometry, Forced vital capacity, Variability, Disease progression

\footnotetext{
* Correspondence: gabriela.leuschner@med.uni-muenchen.de

'Department of Internal Medicine V, Ludwig-Maximilian University Munich,

Marchioninistrasse 15, 81377 Munich, Germany

${ }^{2}$ Comprehensive Pneumology Center (CPC-M), Ludwig-Maximilian University,

and Helmholtz Center Munich, Member of the German Center for Lung

Research (DZL), Munich, Germany

Full list of author information is available at the end of the article
}

\section{$\triangle B M C$}

(c) The Author(s). 2020 Open Access This article is licensed under a Creative Commons Attribution 4.0 International License, which permits use, sharing, adaptation, distribution and reproduction in any medium or format, as long as you give appropriate credit to the original author(s) and the source, provide a link to the Creative Commons licence, and indicate if changes were made. The images or other third party material in this article are included in the article's Creative Commons licence, unless indicated otherwise in a credit line to the material. If material is not included in the article's Creative Commons licence and your intended use is not permitted by statutory regulation or exceeds the permitted use, you will need to obtain permission directly from the copyright holder. To view a copy of this licence, visit http://creativecommons.org/licenses/by/4.0/ The Creative Commons Public Domain Dedication waiver (http://creativecommons.org/publicdomain/zero/1.0/) applies to the data made available in this article, unless otherwise stated in a credit line to the data. 


\section{Background}

Interstitial lung disease (ILD) is a term for a group of conditions including idiopathic pulmonary fibrosis (IPF). Fibrotic ILD such as IPF are all characterized by fibrotic destruction of the lung parenchyma but with great heterogeneity with respect to clinical presentation and prognosis. Furthermore, the individual clinical course of fibrotic ILD can be highly variable, presenting as stable, slowly progressive or rapidly progressive disease [1]. Although therapeutic and diagnostic options for ILD have improved in recent years, the prognosis, especially for IPF, still remains poor [2]. Within a few years of diagnosis, patients can experience dyspnea, hypoxemia and respiratory failure [3]. Patients with progressive, fibrotic ILD suffer from major reductions in quality of life and poor survival, similar to certain malignancies [4]. A reduced forced vital capacity (FVC) has been shown to be the most reliable risk factor for disease progression [5, 6]; indeed, in IPF a FVC decline of 5-10\% over 6 months is associated with an increased risk of mortality [6].

In addition to variation in the disease course between patients with fibrotic ILD, disease-related symptoms can be highly variable within a patient. An acute respiratory deterioration is for example seen in the event of an acute exacerbation $[7,8]$, which has been reported to have a one-year incidence of $3.3-11.5 \%$ in non-IPF ILD $[9,10]$, and $14.2-19.0 \%$ in advanced IPF [7, 11]. Importantly, acute exacerbations are associated with an increased mortality risk in IPF and non-IPF ILD [8]. As a consequence of the variable respiratory status, hospital-based pulmonary function tests, which are usually performed every three to six months as part of the routine care of ILD, may not fully capture the extent of the disease. It has been shown that in patients with IPF, daily domiciliary spirometry to measure FVC can be highly clinically informative by potentially helping to detect patients at risk for acute exacerbations, or to monitor the effectiveness of novel therapies $[12,13]$. In addition, daily domiciliary spirometry offers the opportunity for a more detailed insight into FVC-changes, and of potential disease progression. For example, in lung transplantation recipients, daily spirometry can identify patients with rapid deterioration, especially those at increased mortality risk [14].

Recently, home spirometry was included in a randomized controlled phase II study with fibrotic unclassifiable ILD [15]. Furthermore, the usefulness of home spirometry was studied in ten patients with sarcoidosis and showed good feasibility [16]. Another very recently published study investigated diurnal variations in FVC using home spirometry in patients with different fibrotic ILDs [17]. Beyond that, home spirometry has not been studied in ILD other than IPF, so far, and literature on home spirometry is still limited. Therefore, the aim of this study was to determine feasibility in different types of fibrotic non-IPF ILD and investigate the clinical impact of daily home spirometry in patients with progressive ILD with respect to disease progression.

\section{Methods \\ Study patients}

Individuals with a consensus diagnosis of fibrotic ILD (IPF or non-IPF) [18-20], and subjective clinical progression were recruited from May 2017 until August 2018 in the in- and out-patient unit of the Department of Internal Medicine $\mathrm{V}$ of the University of Munich. Subjective clinical progression was defined as an increase of dyspnea and/or physical limitations within the last six months. Patients with pulmonary obstruction (forced expiratory volume in $1 \mathrm{~s}<70 \%$ ) were not included. This study was conducted in accordance with the amended Declaration of Helsinki. Our study was approved by the local ethics committee of the University of Munich (UE No. 812-16) and all participants provided signed, informed consent. Patients were followed for six months, or until death or lung transplantation.

\section{Study design}

Patients were asked to perform daily home spirometry for six months. Hospital-based lung function testing (comprising spirometry, plethysmography and gas transfer), 6-min walking distance, and clinical assessments were performed at baseline, after three and six months. Subjects were also asked to fill out the St. George's Respiratory Questionnaire (SGRQ), the King's Brief Interstitial Lung Disease (K-BILD) questionnaire and a $10 \mathrm{~cm}$ visual analogue scale (VAS) for cough [21-24].

\section{Spirometry}

Study participants were provided with the hand-held spirometer mySpiroSense ${ }^{\circ}$ (PARI GmbH, Starnberg, Munich), which conforms with international standards [25]. The spirometer measures FVC by means of a turbine volume transducer and provides a digital read out registered in litres at pressure saturated water vapor (BTPS) and body temperature. Patients received $30 \mathrm{~min}$ of instruction on how to perform spirometry, which was repeated at the three month visit. The individual baseline reference values were obtained by using the best FVC from three technically adequate, supervised forced expiratory maneuvers with mySpiroSense ${ }^{ø}$ after patients had demonstrated acceptable technique [25]. Patients were asked to perform, if possible, three spirometry maneuvers at approximately the same time of the day every day, with the best value for each day used for further analysis. Patients were unblinded for their own home spirometry results (digital display). Data were recorded on the spirometer and read out and documented 
electronically at the three and six month hospital visit. Flow-volume curves were also documented by the spirometer and reviewed to ensure validity. The quality of measurements was assessed based on these flow-volume curves and only measurements with good quality flow-volume curves were included in the study. Adherence was calculated as the number of days with home readings divided by the days enrolled in the study, as described before [13].

\section{Statistical analysis}

Continuous variables are presented as the mean \pm standard deviation (SD), with categorical variables summarized by frequency and percentage. The Wilcoxon rank sum test was used to compare continuous variables, with chi square tests or fisher's exact tests used to compare categorial variables. Bland-Altman plots were used to compare hospital-based and home spirometry. Pearson's correlation coefficient was used to correlate hospital spirometry and home spirometry. The hospital-based FVC value was compared to the mean of seven home spirometry FVCs from the respective week at baseline, three months and six months [12, 26]. Individual FVC variability was calculated using the coefficient of variation $(\mathrm{CoV})$ of all home spirometry values within the first 28 days. Additionally, taking potential disease progression into account, individual FVC variability was analysed over three months using the $\mathrm{CoV}$ with detrended data points by fitting a linear regression model on individual patients FVC over time and subtracting the residuals, as described before [26]. Pearson correlation was used to compare FVC CoV of the first 28 days, the following 28 days and the 28 days following the three months visit. A linear regression model was applied using only available values without imputation to calculate individual FVC slopes measured by home spirometry or hospital-based spirometry. Slopes of home and hospital-based spirometry were analysed using the pearson's correlation coefficient. Disease progression was defined as death due to respiratory failure, lung transplantation, acute exacerbation or hospital-based FVC decline $>10 \%$ relative at the three or six months visit. Cox proportional hazard regression analysis was applied to identify associations of FVC variability and disease progression including the covariates baseline FVC, age and gender. The R-function "ctree" of the package "party" was used to define a cutoff value of FVC $\mathrm{CoV}$ for survival analysis. The Kaplan-Meier method was used to evaluate progression- and transplant-free survival time in the study population, with a log-rank test used to analyse differences between groups. $P$ values $<0.05$ were considered statistically significant. Data were analysed using SPSS version 25.0 (IBM SPSS, Armonk, NY) or GraphPad Prism version 8.0 for Mac (GraphPad Software, San Diego, California).

\section{Results}

Study cohort

Of 74 patients, who were screened for eligibility for the study from May 2017 until August 2018, 47 patients (IPF $n=20$; non-IPF $n=27$ ) were included in the study as depicted in Fig. 1. Non-IPF patients had connective tissue disease-related ILD $(n=10)$, chronic hypersensitivity pneumonitis $(n=7)$, unclassifiable $\operatorname{ILD}(n=6)$ or non-specific idiopathic pneumonia $(n=4)$. The IPF cohort was more likely to be male than the non-IPF cohort $(80.0 \%$ vs. $44.4 \% ; p=0.014)$, and was older $(67.7 \pm 7.2$ years vs. $59.0 \pm 12.7$ years; $p=0.009$ ) (Table 1 ). The overall mean \pm SD FVC was $63.8 \pm 20.9 \%$ predicted $(2.3 \pm 0.8$ L), and did not differ between IPF and non-IPF patients. During the study, the majority of patients received medical treatment (IPF $75.0 \%$ antifibrotic therapy; non-IPF: $66.7 \%$ immunosuppressive therapy).

\section{Acceptance, adherence and validity of daily home spirometry}

Acceptance of home spirometry was high, with only four patients (8.5\%; IPF: $n=2$; non-IPF $\mathrm{n}=2$ ) discontinuing within the first week as they were unable to perform daily measurements due to dyspnea. In comparison to the remaining 43 patients, the patients who were not able to perform daily spirometry were significantly older (72.3 \pm 7.0 years vs. $61.3 \pm 11.4$ years; $p=0.042)$. One patient had technical problems with the spirometer within the first 28 days and in two patients more than $50 \%$ of the measurements were of poor quality and had to be excluded. Therefore, only 40 patients were included in further analyses $(\geq 50 \%$ of measurements in the first 4 weeks). These 40 patients participated for a mean \pm SD of $161 \pm 38$ days ( $\min 28$; $\max 231$ days) in the study, performing home spirometry measurements on a mean of $81.8 \pm 18.4 \%$ days and $98.4 \pm 3.5 \%$ of these measurements were of good quality. As shown in Figs. 1, 34 patients completed the full set of six months home spirometry. In these patients, adherence was higher within the first three months compared to the second three months $(83.5 \pm 19.6 \%$ vs. $78.4 \pm 22.3 \%$ of the days; $p=0.0086)$ and did not correlate with patients' age.

There was a strong correlation between the baseline hospital FVC value, and the mean of the home FVC measurements over the first seven days $(r=0.96 ; p<$ 0.0001 ), as well as good overall agreement (bias $0.057 \mathrm{~L}$; $95 \%$ limits of agreement -0.42 to $0.53 \mathrm{~L}$; Fig. 2). The correlation between hospital FVC values and the mean of the home FVC measurements was similarly strong at the three months $(r=0.95 ; p<0.0001)$ and six months visit $(r=0.93 ; p<0.0001)$.

A full set of six months home and hospital spirometry was available in 34 patients. Using linear regression analysis, the mean $\pm \mathrm{SD}$ change in FVC in these patients 


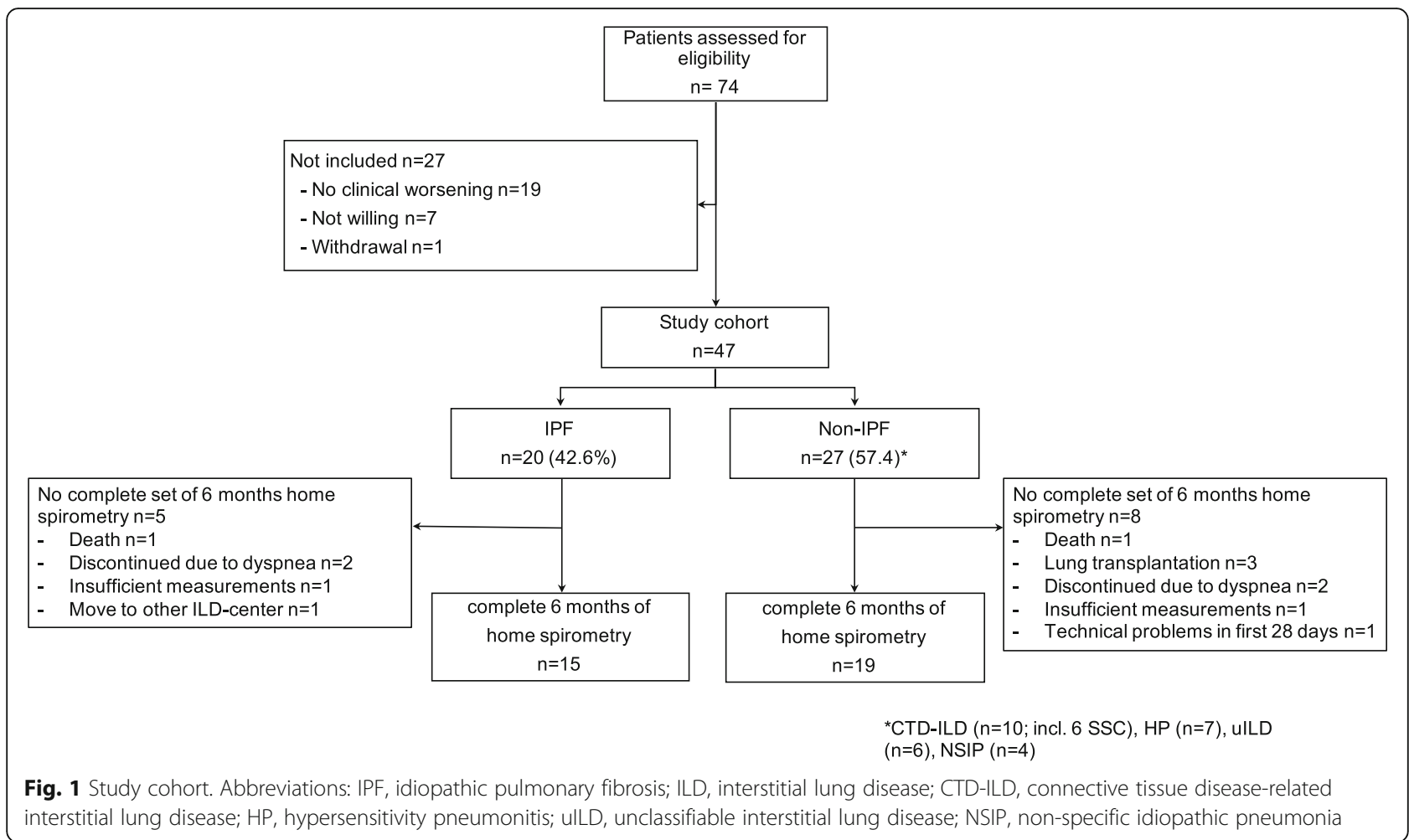

Table 1 Baseline characteristics

\begin{tabular}{|c|c|c|c|}
\hline & $\begin{array}{l}\text { All } \\
(n=47)\end{array}$ & $\begin{array}{l}\text { IPF } \\
(n=20)\end{array}$ & $\begin{array}{l}\text { Non-IPF } \\
(n=27)\end{array}$ \\
\hline Age (years) & $62.7 \pm 11.5$ & $67.7 \pm 7.2$ & $59.0 \pm 12.7$ \\
\hline Gender, male (\%) & $28(59.6)$ & $16(80.0)$ & $12(44.4)$ \\
\hline BMI $\left(\mathrm{kg} / \mathrm{m}^{2}\right)$ & $27.0 \pm 4.5$ & $26.8 \pm 4.7$ & $27.2 \pm 4.5$ \\
\hline \multicolumn{4}{|l|}{ Smoking status } \\
\hline Ex-smoker & $24(51.1)$ & $14(70.0)$ & $10(37.0)$ \\
\hline Pack years & $25.9 \pm 20.5$ & $29.6 \pm 23.2$ & $20.6 \pm 15.6$ \\
\hline \multicolumn{4}{|l|}{ Lung function } \\
\hline FVC, \% predicted & $63.8 \pm 20.9$ & $65.6 \pm 19.1$ & $62.5 \pm 22.4$ \\
\hline FVC (L) & $2.3 \pm 0.8$ & $2.5 \pm 0.8$ & $2.2 \pm 0.8$ \\
\hline TLC, \% predicted & $69.2 \pm 18.8$ & $68.3 \pm 16.9$ & $69.9 \pm 20.5$ \\
\hline TLC (L) & $4.2 \pm 1.1$ & $4.4 \pm 1.2$ & $4.1 \pm 1.0$ \\
\hline DLCO, \% predicted ${ }^{a}$ & $37.8 \pm 15.6$ & $34.5 \pm 15.4$ & $40.1 \pm 15.7$ \\
\hline $6 \mathrm{MWD}(\mathrm{m})^{\mathrm{b}}$ & $380 \pm 121$ & $405 \pm 107$ & $364 \pm 129$ \\
\hline K-BILD & $53.2 \pm 11.4$ & $50.6 \pm 10.6$ & $55.1 \pm 11.9$ \\
\hline$S G R Q^{C}$ & $51.5 \pm 18.2$ & $57.6 \pm 13.0$ & $47.1 \pm 20.3$ \\
\hline VAS cough (cm) & $3.3 \pm 2.6$ & $3.8 \pm 2.7$ & $2.8 \pm 2.4$ \\
\hline
\end{tabular}

Data are presented as mean \pm standard deviation or number (percentage). Definition of abbreviations: 6MWD 6-min walk distance, BMI body mass index, DLCO diffusion capacity for carbon monoxide, FVC forced vital capacity, K-BILD King's Brief Interstitial Lung Disease, SGRQ St George's Respiratory Questionnaire, TLC total lung capacity, VAS visual analogue scale ${ }^{\mathrm{a}} n=30$ patients (IPF: $n=13$; non-IPF: $n=17$ ). ${ }^{\mathrm{b}} n=41$ patients (IPF: $n=16$; non-IPF: $n=25$ ). ${ }^{\complement} n=43$ patients (IPF: $n=18$; non-IPF: $n=25$ )

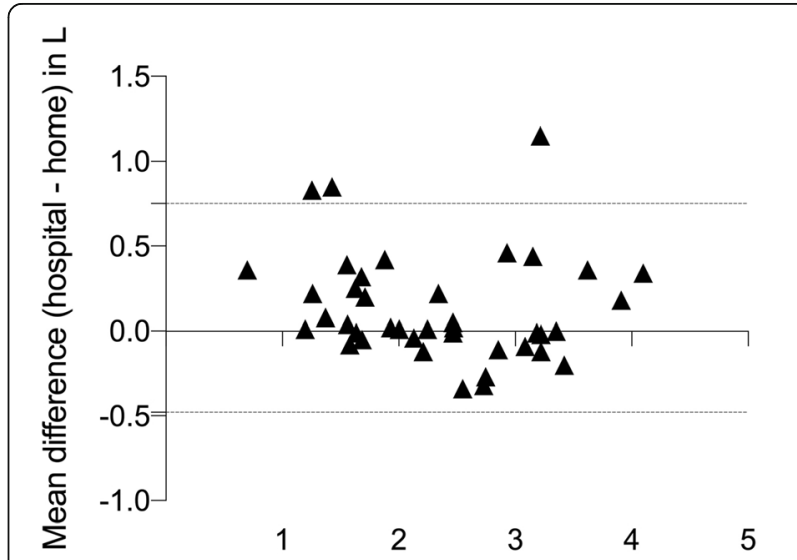

Average of baseline hospital and home FVC $(\mathrm{L})$

Fig. 2 Bland-Altman plot comparing hospital FVC at baseline and home spirometry. Hospital FVC was obtained at the baseline visit; values for home-based FVC are the individual mean of all daily readings within the first seven days of home spirometry. Dashed lines represent the $95 \%$ limits of agreement 
was $-135.1 \pm 303.7 \mathrm{~mL}$ (range -1074.7 to $336.4 \mathrm{~mL}$ ) measured by home spirometry and $-72.4 \pm 227.1 \mathrm{ml}$ (range -672.1 to $424.0 \mathrm{~mL}$ ) measured by hospital-based spirometry. The FVC slopes of home and hospital-based spirometry showed a moderate correlation $(r=0.441$; $p=0.009$ ).

\section{Daily FVC variability}

During the study, 12 patients (30.0\%; IPF: $n=5$; non-IPF $n=7$ ) had a progression of ILD. Examples of individual FVC courses are shown in Fig. 3. Reasons for disease progression were death $(n=2)$, lung transplantation $(n=$ 3 [lung transplantation following acute exacerbation $n=$ 2, lung transplantation following FVC decline $>25 \%: n=$ $1])$, acute exacerbation $(n=1)$ and hospital-based FVC decline $>10 \%(n=6$ [FVC decline $>10 \%$ at three month
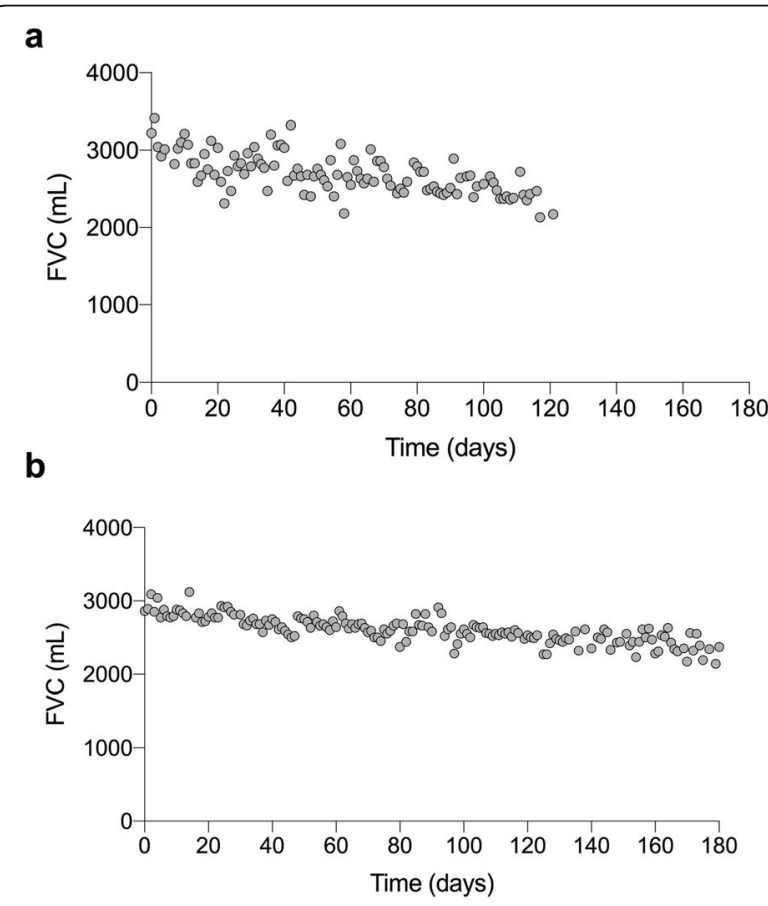

C

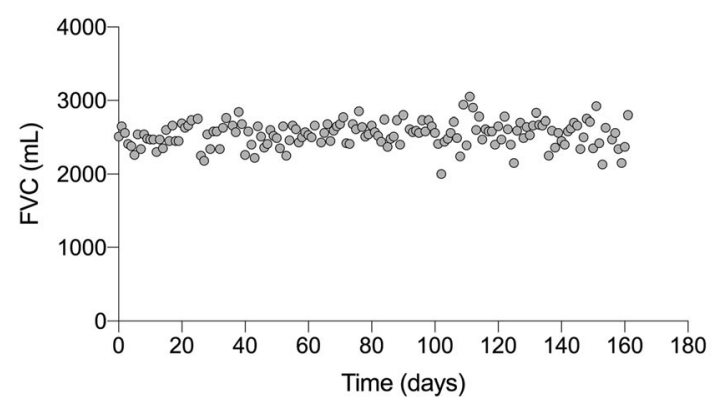

Fig. 3 Individual FVC courses in patients with ILD. a Patient with non-IPF ILD, who died at day 128. b Patient with IPF and FVC decline of $15 \%$ relative over six months. c Patient with non-IPF ILD and stable lung function visit: $n=2$; FVC decline $>10 \%$ at six month visit $n=4]$ ). Of the five IPF patients with disease progression, $80.0 \%$ $(n=4)$ were treated with antifibrotic therapy, of the seven patients with non-IPF, 71.4\% $(n=5)$ had an immunosuppressive therapy at the time of the study. Although at baseline there were no significant differences in age, FVC $\%$ predicted, DLCO, SGRQ or VAS cough between patients with progressive vs. stable disease, the 6MWD $(301 \pm 140 \mathrm{~m}$ vs. $433 \pm 89 \mathrm{~m} ; p=0.009)$ and the K-BILD total score $(46.3 \pm 8.1$ vs. $55.8 \pm 12.7 ; p=0.004)$ were clearly lower in the progressive group, indicating more physical and subjective wellbeing limitations (Table 2).

However, a group of patients had high variability in daily FVC. In the first 28 days (adherence $90.3 \pm 12.0 \%$ ), $60.0 \%$ of the patients had FVC CoV $\geq 5$ and $15.0 \%$ had FVC $\mathrm{CoV} \geq 10 \%$ (Fig. 4). The median of all individual FVC CoVs was $5.9 \%$, ranging from 3.5 to $17.8 \%$. The extent of variation differed clearly between the progressive and stable groups: The median FVC CoV was $8.6 \%$ (min $3.5 \%$, max $17.8 \%$ ) in the progressive group and $4.8 \%$ $(\min 3.5 \%, \max 13.9 \%)$ in the stable group (Fig. $5 ; p=$ 0.002). There was no relationship between $\mathrm{CoV}$ and underlying ILD disease entity. Further, the FVC CoV did not differ between patients treated and not treated with antifibrotic therapy $(p=0.91)$.

To evaluate reproducibility and the potential influence of learning effects on FVC variability, a correlation analysis was performed which showed a strong correlation between the FVC CoV of the first 28 days and the following 28 days $(r=0.79 ; p<0.001)$, as well as a strong correlation between the FVC CoV of the first 28 days and the 28 days following the three months visit $(r=$ $0.82 ; p<0.001)$. There was no significant difference between the mean \pm SD FVC CoV of the first 28 days and the following 28 days (first 28 days: $6.7 \pm 3.3$; following 28 days: $6.1 \pm 3.0 ; p=0.40$ ). In patients, for whom the

Table 2 Baseline clinical characteristics of patients with stable or progressive disease

\begin{tabular}{|c|c|c|c|c|}
\hline & $\begin{array}{l}\text { All } \\
(n=40)\end{array}$ & $\begin{array}{l}\text { stable } \\
(n=28)\end{array}$ & $\begin{array}{l}\text { progressive } \\
(n=12)\end{array}$ & $p$-value \\
\hline Age (years) & $60.7 \pm 11.3$ & $59.6 \pm 12.6$ & $63.1 \pm 7.6$ & 0.59 \\
\hline FVC, \% predicted & $64.7 \pm 21.7$ & $67.1 \pm 21.9$ & $59.2 \pm 21.1$ & 0.31 \\
\hline DLCO, \% predicted ${ }^{a}$ & $41.2 \pm 19.7$ & $43.1 \pm 21.3$ & $36.3 \pm 18.4$ & 0.33 \\
\hline $6 \mathrm{MWD}(\mathrm{m})^{\mathrm{b}}$ & $390 \pm 123$ & $433 \pm 89$ & $301 \pm 140$ & 0.009 \\
\hline $\mathrm{SGRQ}^{\mathrm{C}}$ & $52.8 \pm 18.9$ & $55.2 \pm 19.4$ & $48.0 \pm 17.7$ & 0.18 \\
\hline K-BILD & $52.9 \pm 12.2$ & $55.8 \pm 12.7$ & $46.3 \pm 8.1$ & 0.004 \\
\hline VAS cough & $3.3 \pm 2.6$ & $2.8 \pm 2.5$ & $4.4 \pm 2.5$ & 0.06 \\
\hline
\end{tabular}

Data are presented as mean \pm standard deviation. Definition of abbreviations: 6MWD 6-min walk distance, DLCO diffusion capacity for carbon monoxide, FVC forced vital capacity, K-BILD King's Brief Interstitial Lung Disease, SGRQ St George's Respiratory Questionnaire, VAS visual analog scale

${ }^{a} n=26$ patients (stable: $n=19$; progressive: $n=7$ ); ${ }^{\mathrm{b}} n=34$ patients (stable: $n=23$; progressive: $n=11$ ); ${ }^{\mathrm{C}} n=37$ patients (stable: $n=25$; progressive: $n=12$ ); 


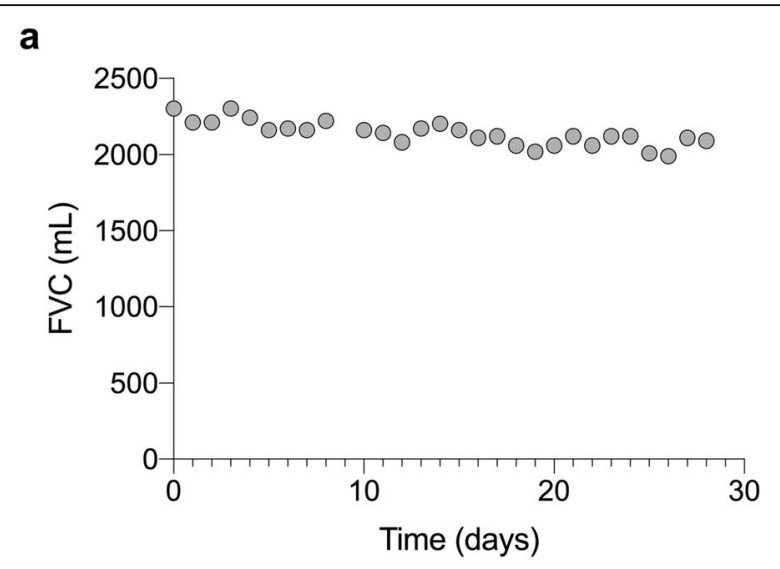

b

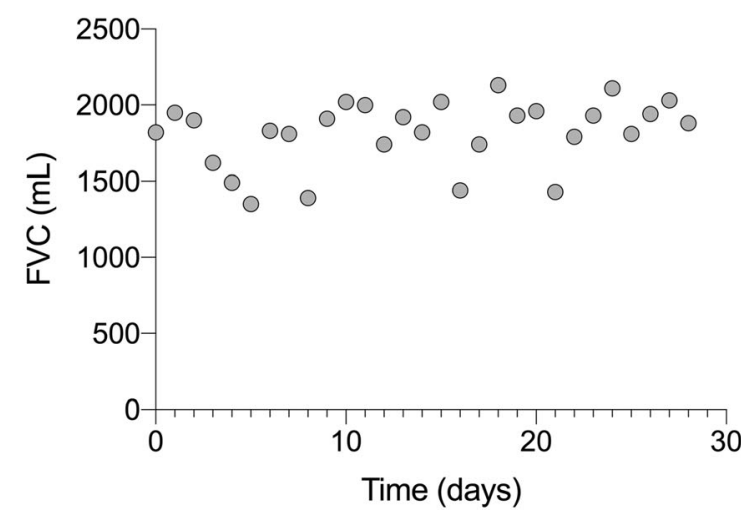

Fig. 4 Different variability of daily FVC among representative patients within 28 days. a Patient with low variability in FVC (3.7\% FVC CoV). b Patient with high variability in FVC $(11.9 \%$ FVC CoV)

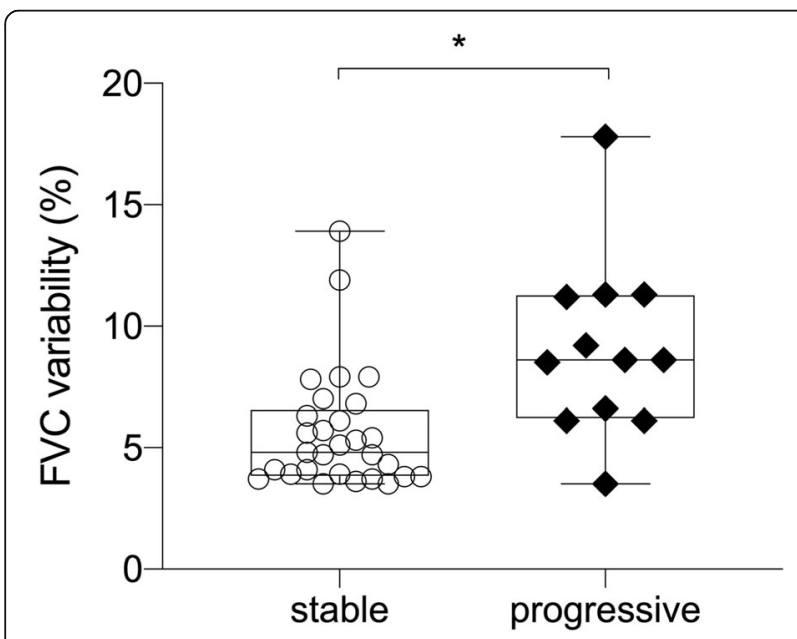

Fig. 5 FVC variability in patients with stable and progressive disease. Progressive patients showed a significantly higher FVC variability within the first 28 days of home spirometry in comparison to stable patients $(p=0.002)$
FVC CoV following the three months visit was available $(n=34)$, there was also no significant difference between the FVC CoV in the first 28 days and the $\mathrm{CoV}$ following the three months visit (first 28 days: $6.5 \pm 3.3$; 28 days following three months visit: $6.2 \pm 2.9 ; p=0.63$ ). Furthermore, to assure that variability was not driven by shortterm lung function deterioration, the $\mathrm{FVC} \mathrm{CoV}$ and the slope of FVC within the first 28 days were correlated and showed no relationship $(r=-0.26 ; p=0.11)$.

To assess whether FVC variability can also be observed over a longer observation period, the $\mathrm{CoV}$ was further analysed over three months with detrended data points. FVC variability over three months showed a strong correlation with the FVC variability over 28 days $(r=0.936 ; p<0.001)$. Also, over three months, patients with disease progression had significantly higher FVC variability compared to stable patients $(8.4 \pm 3.2 \%$ vs. $5.5 \pm 2.5 \% ; p=0.002$ ).

To see whether patients with disease progression had also higher FVC variability in hospital-based spirometry we further analysed the 34 patients, who had a full set of six months home and hospital spirometry. Of these, seven had a disease progression. The $\mathrm{CoV}$ with detrended data points of the three hospital FVCs (baseline, three months and six months) did not significantly differ between the progressive and the stable patients $(4.2 \pm 3.9 \%$ vs. $2.6 \pm 2.8 \% ; p=0.391)$.

\section{Disease progression}

FVC variability over 28 days was independently associated with disease progression (HR 1.203; 95\% CI: 1.050-1.378; $p=0.0076)$ while the covariates baseline FVC, age and gender were no significant predictors in the regression analysis in this cohort (Table 3). The optimal cutoff to differentiate between patients with low and high variability was found to be $7.9 \%$. A progress of ILD was found in $14.3 \%(n=4)$ of the patients with low variability $(<7.9 \%$ rel.) and in $66.7 \%(n=8)$ of the patients with high variability $(\geq 7.9 \%$ rel.). In the Kaplan-Meier survival analysis, while the six months progression- and transplant-free survival rate was $77.2 \%$ in patients with low variability $(<7.9 \%$ rel.), it was $37.5 \%$ in patients with high variability $(\geq 7.9 \%$ rel.; $p=0.003$; Fig. 6). FVC variability over three months

Table 3 Cox proportional hazard regression analysis assessing the effect on disease progression

\begin{tabular}{llll}
\hline & Hazard Ratio & $\mathbf{9 5 \% - C l}$ & $\boldsymbol{p}$-value \\
\hline Age & 1.036 & $0.951-1.130$ & 0.416 \\
gender & 0.655 & $0.160-2.682$ & 0.556 \\
Baseline FVC, \% predicted & 0.997 & $0.954-1.041$ & 0.876 \\
FVC variability & 1.203 & $1.050-1.378$ & $\mathbf{0 . 0 0 7 6}$
\end{tabular}

FVC variability was assessed over 28 days

Definition of abbreviations: $C l$ confidence interval, $F V C$ forced vital capacity 


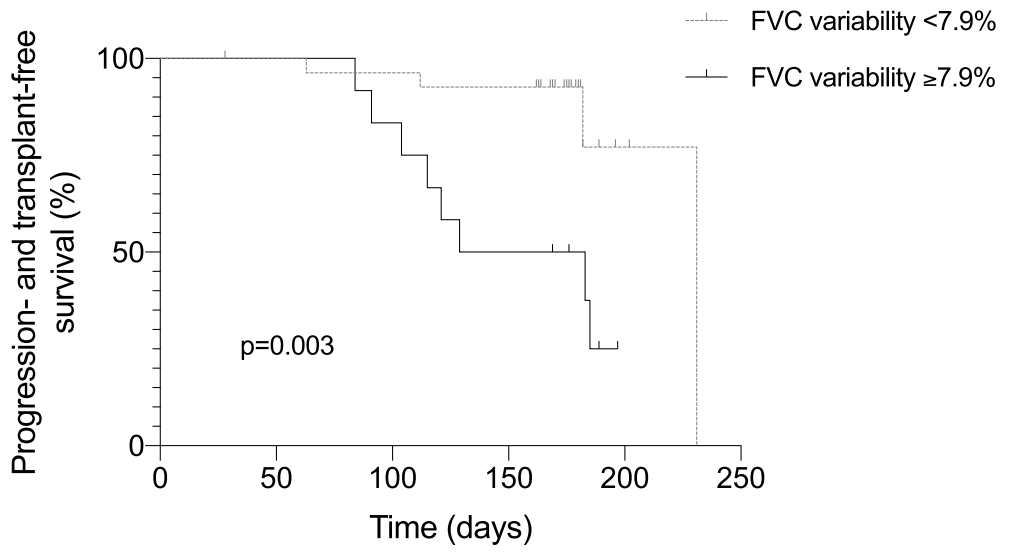

Fig. 6 Progression- and transplant-free survival in patients with low and high FVC variability. Based on the optimal cut-off of 7.9\%, patients with high FVC variability $(\geq 7.9 \%)$ had significantly shorter progression- and transplant-free survival compared to patients with low FVC variability $(<7.9 \% ; p=0.003)$

was also a significant predictor for disease progression in the regression analysis with the covariates baseline FVC, age and gender (HR: $1.290 ; 95 \%$-CI: $1.013-1.643 ; p=0.039)$.

\section{Discussion}

The clinical course of ILD can be highly variable, and given the unfavorable prognosis of progressive, fibrotic ILD, it is important to identify predictive factors. Recently, it has been shown that daily home spirometry can provide important information about the clinical course in patients with IPF [12]. However, studies on the usefulness in non-IPF ILD are still limited. Our study focused on home spirometry in patients with IPF and various fibrotic non-IPF ILD, and showed that over one month, FVC can vary greatly in these patients. Furthermore, we demonstrated in the present study that FVC variability was associated with disease progression. Daily home spirometry had a high degree of acceptance, although $8.5 \%$ of patients struggled with daily spirometry due to dyspnea and $6.4 \%$ had technical problems or poor quality of measurements.

While hospital-based pulmonary function tests cannot be performed on a daily basis, home spirometry allows us to get a more frequent and deeper insight into the respiratory status of our patients, including FVC variability. As shown earlier, the phenomenon of daily spirometric variability seems to occur more often in patients with lung disease than in healthy controls [27]. Recently, daily FVC variability has also been shown in fibrotic ILDs [17]. The authors of this study identified a diurnal variation with higher FVC values in the morning compared to the afternoon. In line with our observations, two other studies described FVC variability of 0.04 to $0.39 \mathrm{~L}$ over 28 days of home spirometry in patients with IPF $[12,28]$. Indeed, these analyses were only used to evaluate within-subject reproducibility of measurements and were not analysed for their correlation with disease progression [12, 28]. Johannson et al. also observed high variability in FVC in patients with IPF [13], although with home spirometry performed on a weekly basis, and again, variability was not studied in relation to clinical outcome. Interestingly, Russell et al. described a CoV of FVC of 4.96\% (range 2.06$20.9 \%$ ) in IPF patients, which matches our findings [12]. As FVC variability could potentially be caused by factors like spirometry technique (including learning effects), cough, disease progression, mucus production or infection we assessed the relationship between $\mathrm{CoV}$ of the first 28 days and the $\mathrm{CoV}$ of the second 28 days as well as the $\mathrm{CoV}$ of the 28 days following the three months visit and identified a good individual reproducibility. Although the FVC CoV was slightly higher within the first 28 days in comparison to the following 28 days and the 28 days following the three months visit, these differences were not significant. Therefore, in our study, the influence of learning effects (spirometry technique) on the FVC variability appears to be small. Moreover, there was no relationship between $\mathrm{CoV}$ and deterioration of lung function within 28 days. Interestingly, our finding that increased variability is associated with disease progression holds true when the variability is assessed over an extended period of time using the $\mathrm{CoV}$ over three months with detrended data points [26].

Our results raise the question of whether FVC variability might be a previously unknown predictor for disease progression. In fact, in the past, it has been shown several times that baseline FVC is the most reliable predictor of progression in IPF [5, 6, 29-31]. In our study, however, FVC variability was the only significant predictor for ILD disease progression. It should be noted, that for a major effect of other variables (e.g. baseline FVC) the patient number in our study may have been too small. The observed FVC variability could be interpreted as representation of recurrent subclinical FVC 
deterioration. We speculate that in a diseased lung, such as ILD, with physiological changes, respiratory capacity can vary on a daily basis as a sign of a vulnerable lung. In chronic diseases with limited mobility, such as advanced ILD, more frequent doctor appointments with pulmonary function tests are often not feasible. Detecting patients at risk for disease progression might allow us to monitor or initiate new medical therapies earlier or evaluate patients for lung transplantation. This further emphasizes the potential utility of domiciliary spirometry in ILD, especially with respect to clinical decision making. In the future, telemedicine will play an important role in patient care. Recently, a pilot study investigated real-time wireless home spirometry in IPF and found it feasible [28].

An important challenge in the future is that adherence to home spirometry among our patients decreased significantly over time. While the median adherence within the first 28 days was $90 \%$, over six months this dropped to $81 \%$. Interestingly, this was not influenced by a small number of patients with very poor adherence, since at the end of the study, only $41 \%$ still had an adherence of $>90 \%$. Of note, our spirometer did not include any programmed reminders which might have had a positive influence. Nevertheless, the phenomenon of decreasing adherence occurs even with only weekly measurements [13]. Currently, however, parameters like FVC variability can only be assessed through home spirometry. Therefore, tools have to be developed to minimize barriers and motivate patients to perform FVC measurements on a regular basis, as provided by Moor et al. [28]. Furthermore, as a possible outlook for the future, in clinical practice, it might be sufficient to do daily domiciliary assessments for a limited period of time (for example after diagnosis or one month per year) as part of standard care. Finally, a significant challenge in the future is the interpretation of FVC slopes derived from home spirometry over an extended period of time, for example in clinical trials. In our study, slopes of home and hospital spirometry showed a moderate correlation. Overall, home spirometry detected greater changes in FVC than hospital spirometry. In 2019, the data of a large phase II trial with progressive unclassifiable ILD were published, where the mean change in FVC measured by home spirometry was the primary endpoint [15]. Unfortunately, due to technical problems and physiologically implausible measurements, the data of the primary endpoint could not be sufficiently analysed. Therefore, Maher et al. clearly stated, that further assessments are required, before home spirometry can be used regularly in clinical trials [15]. Very recently data of a randomized controlled trial investigating the benefit of a home monitoring program in terms of improved health related quality of life and medication use for patients with IPF was published [26]. In this study by Moor et al. home spirometry was used, including automated e-mail reminders when spirometry was not performed. Over six months, the authors showed a high adherence rate to home spirometry and comparable slopes of home and hospital spirometry. Given these positive results, programmed reminders and real-time feedback indeed might be a helpful tool in the future to improve quality of home spirometry measurements.

The results of our study should be interpreted in view of the study design and its limitations, which include a single-centre setting and a limited number of patients. The small number of patients included in the study makes it difficult to draw definitive conclusions at this point. Our observations on FVC variability must therefore be interpreted rather as hypothesisgenerating and still require validation in separate (multi-centric) studies in the future. Nevertheless, the results of our study should be considered relevant and important as this is the first study to identify daily FVC variability as a potential prognostic factor in ILD. Furthermore, not all patients were able to perform daily spirometry due to dyspnea. Still, this was a real-life experience and our study was designed to include patients with progressive ILD, who presumably would have a high dyspnea burden - and despite this, there was a high level of acceptability of daily spirometry. In line with this finding, in another IPF cohort $13 \%$ of patients were unable to perform home spirometry [13]. However, our study does suggest that home spirometry may not be feasible in all patients with ILD.

\section{Conclusion}

In conclusion, we demonstrated that in ILD, FVC can vary greatly on a daily basis. Moreover, higher FVC variability was associated with disease progression in ILD. Although home spirometry was feasible and accepted in the majority of patients, daily use can be challenging and might not be feasible for all patients in the long term. Nonetheless, home spirometry (even when performed over a limited period) could help to detect patients at risk of disease progression, and so might be beneficial for clinical decision making and in ILD research in the future. Future studies are needed to further determine the role of FVC variability and to evaluate whether it can be used as a biomarker of disease progression in patients with fibrotic ILD.

\section{Abbreviations}

CoV: Coefficient of variation; FVC: Forced vital capacity; ILD: Interstitial lung disease; IPF: Idiopathic pulmonary fibrosis; K-BILD: King's Brief Interstitial Lung Disease Questionnaire; SD: Standard deviation; SGRQ: St. George's Respiratory Questionnaire; VAS: Visual analogue scale 


\section{Acknowledgements}

We thank our patients for their time and commitment to the study. We also thank David Young, a professional medical writer from Young Medical Communications and Consulting Limited, who critically reviewed and language-edited the manuscript prior to submission. Furthermore, we thank Julia Brust, Cristina Kirra and Marlen Wenzel for their administrative support and for instructing the patients on how to use the spirometer. We also thank Philipp Kroneberg and Dr. Arshan Perera from PARI for the support and assistance with mySpiroSense ${ }^{\oplus}$.

\section{Authors' contributions}

TV and GL had full access to all of the data in the study and take responsibility for the integrity of the data and the accuracy of the data analysis. TV, MB, FC, $\mathrm{PA}, \mathrm{DM}, \mathrm{MS}, \mathrm{JBa}, \mathrm{SS}, \mathrm{MF}, \mathrm{KM}$ and GL contributed substantially to the data acquisition. TV, AC, NK, HS, JB, CN and GL contributed substantially to the study design, data analysis and interpretation. TV, AC, NK, JBe, CN and GL were substantially involved in writing of the manuscript. All authors revised the article and approved the final version submitted for publication and agree to be accountable for all aspects of the work.

\section{Funding}

This study was financially supported by research grants from Boehringer Ingelheim, the Friedrich-Baur-Stiftung (Ludwig-Maximilians University Munich) and the German Society "Lungenfibrose e.V". None of the funding bodies was involved in the design of the study, the collection, analysis and interpretation of data or in writing the manuscript. Open Access funding enabled and organized by Projekt DEAL.

\section{Availability of data and materials}

The datasets generated and analysed during the current study are not publicly available due privacy of our patients but are available from the corresponding author on reasonable request.

\section{Ethics approval and consent to participate}

This study was conducted in accordance with the amended Declaration of Helsinki. Our study was approved by the local ethics committee of the University of Munich (UE No. 812-16) and all participants provided signed, informed consent.

\section{Consent for publication}

Not applicable.

\section{Competing interests}

The authors (TV, MB, AC, NK, FC, PA, DM, MS, JBa, SS, HS, MF, KM, JBe, CN and $\mathrm{GL})$ declare that they have no competing interests relevant to this work.

\section{Author details}

${ }^{1}$ Department of Internal Medicine V, Ludwig-Maximilian University Munich, Marchioninistrasse 15, 81377 Munich, Germany. ${ }^{2}$ Comprehensive Pneumology Center (CPC-M), Ludwig-Maximilian University, and Helmholtz Center Munich, Member of the German Center for Lung Research (DZL), Munich, Germany. ${ }^{3}$ IBE - Institute for Medical Information Processing, Biometry and Epidemiology, Ludwig-Maximilian University Munich, Munich, Germany. ${ }^{4}$ Department of Pneumology, Asklepios Fachkliniken

Muenchen-Gauting, Academic Teaching Hospital of the University of Munich, Gauting, Germany. ${ }^{5}$ Department of Pneumology and Respiratory Medicine, Hospital Schillerhoehe, Academic Teaching Hospital of the University of Tuebingen, Gerlingen, Germany.

\section{Received: 26 February 2020 Accepted: 25 September 2020} Published online: 19 October 2020

\section{References}

1. King TE Jr, Pardo A, Selman M. Idiopathic pulmonary fibrosis. Lancet. 2011; 378(9807):1949-61.

2. Park JH, Kim DS, Park IN, Jang SJ, Kitaichi M, Nicholson AG, et al. Prognosis of fibrotic interstitial pneumonia: idiopathic versus collagen vascular disease-related subtypes. Am J Respir Crit Care Med. 2007;175(7):705-11.

3. Raghu G, Collard HR, Egan JJ, Martinez FJ, Behr J, Brown KK, et al. An official ATS/ERS/JRS/ALAT statement: idiopathic pulmonary fibrosis: evidence-based guidelines for diagnosis and management. Am J Respir Crit Care Med. 2011; 183(6):788-824.

4. Bahmer T, Kirsten AM, Waschki B, Rabe KF, Magnussen H, Kirsten D, et al. Prognosis and longitudinal changes of physical activity in idiopathic pulmonary fibrosis. BMC Pulm Med. 2017;17(1):104.

5. Richeldi L, Ryerson CJ, Lee JS, Wolters PJ, Koth LL, Ley B, et al. Relative versus absolute change in forced vital capacity in idiopathic pulmonary fibrosis. Thorax. 2012;67(5):407-11.

6. Zappala CJ, Latsi PI, Nicholson AG, Colby TV, Cramer D, Renzoni EA, et al. Marginal decline in forced vital capacity is associated with a poor outcome in idiopathic pulmonary fibrosis. Eur Respir J. 2010;35(4):830-6.

7. Song JW, Hong SB, Lim CM, Koh Y, Kim DS. Acute exacerbation of idiopathic pulmonary fibrosis: incidence, risk factors and outcome. Eur Respir J. 2011;37(2):356-63.

8. Leuschner G, Behr J. Acute Exacerbation in Interstitial Lung Disease. Front Med (Lausanne). 2017:4:176.

9. Miyazaki Y, Tateishi T, Akashi T, Ohtani Y, Inase N, Yoshizawa Y. Clinical predictors and histologic appearance of acute exacerbations in chronic hypersensitivity pneumonitis. Chest. 2008;134(6):1265-70.

10. Park IN, Kim DS, Shim TS, Lim CM, Lee SD, Koh Y, et al. Acute exacerbation of interstitial pneumonia other than idiopathic pulmonary fibrosis. Chest. 2007;132(1):214-20.

11. Judge EP, Fabre A, Adamali HI, Egan JJ. Acute exacerbations and pulmonary hypertension in advanced idiopathic pulmonary fibrosis. Eur Respir J. 2012; 40(1):93-100.

12. Russell AM, Adamali H, Molyneaux PL, Lukey PT, Marshall RP, Renzoni EA, et al. Daily home Spirometry: an effective tool for detecting progression in idiopathic pulmonary fibrosis. Am J Respir Crit Care Med. 2016;194(8):989-97.

13. Johannson KA, Vittinghoff E, Morisset J, Lee JS, Balmes JR, Collard HR. Home monitoring improves endpoint efficiency in idiopathic pulmonary fibrosis. Eur Respir J. 2017;50(1).

14. Belloli EA, Wang X, Murray S, Forrester G, Weyhing A, Lin J, et al. Longitudinal forced vital capacity monitoring as a prognostic adjunct after lung transplantation. Am J Respir Crit Care Med. 2015;192(2):209-18.

15. Maher TM, Corte TJ, Fischer A, Kreuter M, Lederer DJ, Molina-Molina M, et al. Pirfenidone in patients with unclassifiable progressive fibrosing interstitial lung disease: a double-blind, randomised, placebo-controlled, phase 2 trial. Lancet Respir Med. 2019.

16. Moor CC, Gur-Demirel Y, Wijsenbeek MS. Feasibility of a Comprehensive Home Monitoring Program for Sarcoidosis. J Pers Med. 2019;9(2).

17. Moor CC, van den Berg CAL, Visser LS, Aerts J, Cottin V, Wijsenbeek MS. Diurnal variation in forced vital capacity in patients with fibrotic interstitial lung disease using home spirometry. ERJ Open Res. 2020;6(1).

18. Raghu G, Remy-Jardin M, Myers JL, Richeldi L, Ryerson CJ, Lederer DJ, et al. Diagnosis of idiopathic pulmonary fibrosis. An official ATS/ERS/ JRS/ALAT clinical practice guideline. Am J Respir Crit Care Med. 2018; 198(5):e44-68.

19. Travis WD, Costabel U, Hansell DM, King TE Jr, Lynch DA, Nicholson AG, et al. An official American Thoracic Society/European Respiratory Society statement: update of the international multidisciplinary classification of the idiopathic interstitial pneumonias. Am J Respir Crit Care Med. 2013;188(6): 733-48.

20. Sennekamp J, Muller-Wening D, Amthor M, Baur X, Bergmann KC, Costabel $U$, et al. Guidelines for diagnosing extrinsic allergic alveolitis (hypersensitivity pneumonitis) (German Extrinsic Allergic Alveolitis Study Group). Pneumologie (Stuttgart, Germany). 2007;61(1):52-6.

21. Furukawa $T$, Taniguchi $H$, Ando M, Kondoh $Y$, Kataoka K, Nishiyama O, et al. The St. George's Respiratory Questionnaire as a prognostic factor in IPF. Respir Res. 2017;18(1):18.

22. Kreuter M, Birring SS, Wijsenbeek M, Wapenaar M, Oltmanns U, Costabel U, et al. German Validation of the "King's Brief Interstitial Lung Disease (K-Bild) Health Status Questionnaire". Pneumologie (Stuttgart, Germany). 2016; 70(11):742-6.

23. Patel AS, Siegert RJ, Brignall $K$, Gordon $P$, Steer $S$, Desai SR, et al. The development and validation of the King's brief interstitial lung disease (KBILD) health status questionnaire. Thorax. 2012;67(9):804-10.

24. Morice AH, Fontana GA, Belvisi MG, Birring SS, Chung KF, Dicpinigaitis PV, et al. ERS guidelines on the assessment of cough. Eur Respir J. 2007;29(6): 1256-76.

25. Miller MR, Hankinson J, Brusasco V, Burgos F, Casaburi R, Coates A, et al. Standardisation of spirometry. Eur Respir J. 2005;26(2):319-38. 
26. Moor CC, Mostard RLM, Grutters JC, Bresser P, Aerts J, Chavannes NH, et al. Home monitoring in patients with idiopathic pulmonary fibrosis. A randomized controlled trial. Am J Respir Crit Care Med. 2020;202(3):393-401.

27. Rozas CJ, Goldman AL. Daily spirometric variability: normal subjects and subjects with chronic bronchitis with and without airflow obstruction. Arch Intern Med. 1982;142(7):1287-91.

28. Moor CC, Wapenaar M, Miedema JR, Geelhoed JJM, Chandoesing PP, Wijsenbeek MS. A home monitoring program including real-time wireless home spirometry in idiopathic pulmonary fibrosis: a pilot study on experiences and barriers. Respir Res. 2018;19(1):105.

29. du Bois RM, Weycker D, Albera C, Bradford WZ, Costabel U, Kartashov A, et al. Forced vital capacity in patients with idiopathic pulmonary fibrosis: test properties and minimal clinically important difference. Am J Respir Crit Care Med. 2011;184(12):1382-9.

30. du Bois RM, Weycker D, Albera C, Bradford WZ, Costabel U, Kartashov A, et al. Ascertainment of individual risk of mortality for patients with idiopathic pulmonary fibrosis. Am J Respir Crit Care Med. 2011;184(4):459-66.

31. Nathan SD, Shlobin OA, Weir N, Ahmad S, Kaldjob JM, Battle E, et al. Longterm course and prognosis of idiopathic pulmonary fibrosis in the new millennium. Chest. 2011;140(1):221-9.

\section{Publisher's Note}

Springer Nature remains neutral with regard to jurisdictional claims in published maps and institutional affiliations.

Ready to submit your research? Choose BMC and benefit from:

- fast, convenient online submission

- thorough peer review by experienced researchers in your field

- rapid publication on acceptance

- support for research data, including large and complex data types

- gold Open Access which fosters wider collaboration and increased citations

- maximum visibility for your research: over $100 \mathrm{M}$ website views per year

At BMC, research is always in progress.

Learn more biomedcentral.com/submissions 